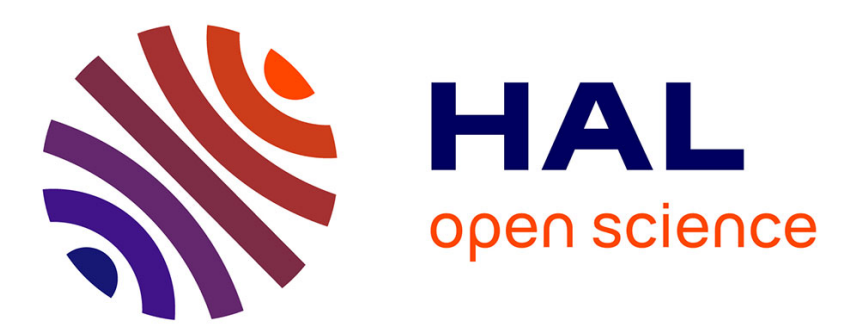

\title{
Impact of $\mathrm{BaB} 2 \mathrm{O} 4$ growth method on frequency conversion to the deep ultra-violet
}

Loic Deyra, Alain Maillard, R Maillard, D Sangla, F Salin, François

Balembois, A.E. Kokh, Patrick Georges

\section{To cite this version:}

Loic Deyra, Alain Maillard, R Maillard, D Sangla, F Salin, et al.. Impact of BaB 2 O 4 growth method on frequency conversion to the deep ultra-violet. Solid State Sciences, 2015, 50, pp.97-100. 10.1016/j.solidstatesciences.2015.10.019 . hal-01227105

\section{HAL Id: hal-01227105 \\ https://hal.science/hal-01227105}

Submitted on 10 Nov 2015

HAL is a multi-disciplinary open access archive for the deposit and dissemination of scientific research documents, whether they are published or not. The documents may come from teaching and research institutions in France or abroad, or from public or private research centers.
L'archive ouverte pluridisciplinaire HAL, est destinée au dépôt et à la diffusion de documents scientifiques de niveau recherche, publiés ou non, émanant des établissements d'enseignement et de recherche français ou étrangers, des laboratoires publics ou privés. 


\section{Accepted Manuscript}

Impact of $\mathrm{BaB}_{2} \mathrm{O}_{4}$ growth method on frequency conversion to the deep ultra-violet

L. Deyra, A. Maillard, R. Maillard, D. Sangla, F. Salin, F. Balembois, A.E. Kokh, P. Georges

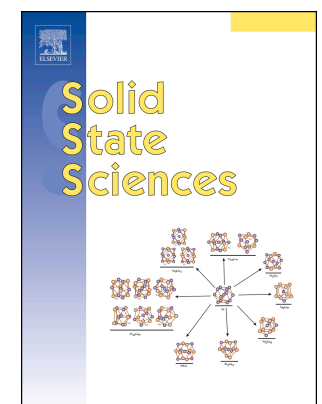

PII: S1293-2558(15)30076-5

DOI: $\quad$ 10.1016/j.solidstatesciences.2015.10.019

Reference: SSSCIE 5226

To appear in: Solid State Sciences

Received Date: 5 March 2015

Revised Date: 18 September 2015

Accepted Date: 28 October 2015

Please cite this article as: L. Deyra, A. Maillard, R. Maillard, D. Sangla, F. Salin, F. Balembois, A.E. Kokh, P. Georges, Impact of $\mathrm{BaB}_{2} \mathrm{O}_{4}$ growth method on frequency conversion to the deep ultra-violet, Solid State Sciences (2015), doi: 10.1016/j.solidstatesciences.2015.10.019.

This is a PDF file of an unedited manuscript that has been accepted for publication. As a service to our customers we are providing this early version of the manuscript. The manuscript will undergo copyediting, typesetting, and review of the resulting proof before it is published in its final form. Please note that during the production process errors may be discovered which could affect the content, and all legal disclaimers that apply to the journal pertain. 


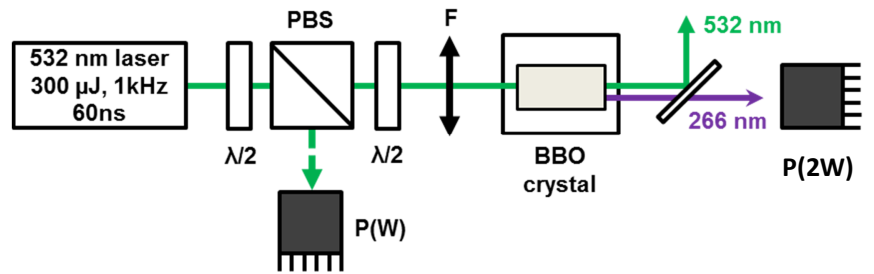

Czochralski and TSSG $\beta$-BBO crystals are compared for high power UV $(266 \mathrm{~nm})$ in second harmonic generation. Impurities from flux decrease the efficiency of harmonic generation at high power (40\%).

Output power at

$257 \mathrm{~nm}(\mathrm{~W})$

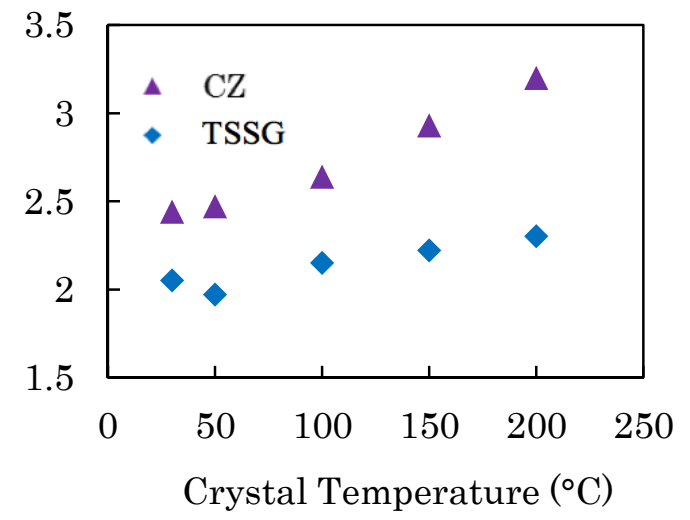




\title{
Impact of $\mathrm{BaB}_{2} \mathrm{O}_{4}$ growth method on frequency conversion to the deep ultra-violet.
}

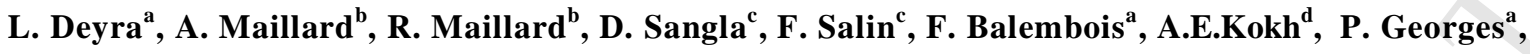 \\ a. Laboratoire Charles Fabry, Institut d'Optique, CNRS, Univ Paris-Sud, 91127 Palaiseau, France \\ b. Laboratoire Matériaux Optiques Photonique et Systèmes, Université de Lorraine, CentraleSupelec 57070 Metz, France \\ c. EOLITE Systems, Cité de la Photonique, 11 avenue canteranne, 33600 Pessac, France \\ d. Sobolev Institute of Geology and Mineralogy SB RAS, 630090, Novosibirsk, Russia \\ Corresponding author : A Maillard, alain.maillard@univ-lorraine.fr
}

\begin{abstract}
In this article, we report how the growth method used for barium beta-borate $\beta-\mathrm{BaB}_{2} \mathrm{O}_{4} \quad(\mathrm{BBO})$ impacts its high power second harmonic generation properties in the deep-UV. We compared a BBO crystal grown by flux (Top Seeded Solution Growth or TSSG) and a BBO crystal grown by the Czochralski (CZ) method. We first characterized their transparency properties, then we measured their single-pass second harmonic conversion efficiencies with both a low average power and a high average power nanosecond pulsed lasers. We show that both crystals have comparable linear absorption and conversion efficiencies at low power, whereas in a high power experiment, the CZ-grown BBO yields higher conversion efficiency than the TSSG grown BBO. With a $30 \mathrm{~W}, 150 \mathrm{kHz}$, 8ns green laser, the use of a CZ BBO led at best to a $40 \%$ increase in available average output power at $257 \mathrm{~nm}$.
\end{abstract}

Keywords: Borates, Nonlinear optical, Czochralski growth, Solution growth, Second harmonic generation.

\section{Introduction}

The material machining industry has continuously looked to process more and more types of materials efficiently. For some of them such as silicon, glass, sapphire, the ultraviolet lasers (UV) were developed in order to increase the material absorption [1,2]. While UV lasers around $350 \mathrm{~nm}$ obtained by third harmonic generation (THG) are now commonly used in material processing, deep-UV lasers obtained by fourth harmonic generation (FHG) around $260 \mathrm{~nm}$ are still challenging to realize. The nonlinear material quality is a key parameter in order to reach high and stable conversion efficiency by reducing thermal dephasing and degradation effects. Beta-barium borate $\beta-\mathrm{BaB}_{2} \mathrm{O}_{4}(\mathrm{BBO})$ is a nonlinear crystal that has good properties for frequency conversion to the UV, such as a high nonlinearity or a short cut-off wavelength in the UV around 190nm [3]. It is available commercially, and is usually grown by top-seeded solution growth (TSSG) assisted with either a $\mathrm{Na}_{2} \mathrm{O}$ or $\mathrm{NaF}$ flux [4]. $\mathrm{BBO}$ can be also grown without flux by the Czochralski (CZ) method, but it is more difficult and produces smaller crystal boules [5]. Several previous works argued that the CZ-grown BBO had better properties when used for frequency conversion to the UV. Umezu and al reported in 1998 that CZ-BBO lead to an improved laser lifetime, but without showing any material characterization [6]. In 2012, Bandhari and al reported a 3 MW peak power $266 \mathrm{~nm}$ microchip laser based on fluxless-grown BBO. They showed a comparison between flux-grown and CZ BBO, and demonstrated that a CZ-grown BBO had a significantly lower linear absorption than fluxgrown BBO, which led to an improvement in the final conversion efficiency [7]. Nonetheless, the flux-grown BBO had an unusually high absorption value at $266 \mathrm{~nm}$ of $\alpha=0.143 \mathrm{~cm}^{-1}$. Moreover, the improvement of the BBO transparency was explained by a combination of several factors not only linked to the $\mathrm{CZ}$ growth method.

In this paper, we investigate if the $\mathrm{CZ}$ growth of BBO intrinsically leads to an improved crystal quality, and if this improved quality can lead to enhance performances during high-power fourth harmonic generation to the deep-UV at $257 \mathrm{~nm}$.

2. Crystals considerations.

Two crystals have been investigated during this experiment. A flux-grown BBO was purchased (TSSG). The Czochralski BBO (CZ) was grown at the LMOPS laboratory (Metz). We synthesized $\mathrm{BaB}_{2} \mathrm{O}_{4}$ by the following solid phase chemical reaction from standard purity raw materials, $\mathrm{BaCO}_{3}$ (Alfa Aesar 99.95\%) and $\mathrm{B}_{2} \mathrm{O}_{3}$ (Alfa Aesar 99.98\%) :

$$
\mathrm{BaCO}_{3}+\mathrm{B}_{2} \mathrm{O}_{3} \rightarrow \mathrm{BaB}_{2} \mathrm{O}_{4}+\mathrm{CO}_{2} \uparrow
$$

A standard Czochralski type crystal growing apparatus with radio frequency (RF) heated furnace and without automatic diameter control was employed. The melt had to be super-cooled near $1050^{\circ} \mathrm{C}$ for the nucleation of the $\beta$ phase. In our apparatus the radial temperature gradient was measured to be about $28 \% \mathrm{~cm}$. The vertical temperature gradient was adjusted to $550 \% \mathrm{~cm}$ at the surface of the melt. The seed was oriented along the c axis and its bottom surface 
was polished and etched with ortho-phosphoric acid at $100^{\circ} \mathrm{C}$ for $1 \mathrm{mn}$ to eliminate stress on the surface [5]. A $50 \mathrm{~mm}$ high platinum crucible with a diameter of $50 \mathrm{~mm}$ was used. The typical rotation speed is $4 \mathrm{rpm}$. With a pulling rate of $0.5 \mathrm{~mm} / \mathrm{h}$, a $58 \mathrm{~g}$ bowl was obtained as shown Figure 1 .
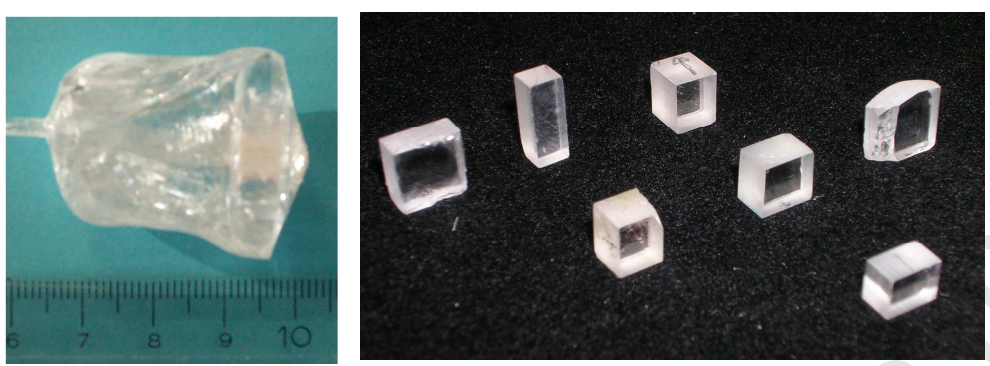

Figure 1: Czochralski $\square$-BBO grown in super cooled melt (left). Samples are sawn from clear and less stress part of the bowl. Oriented and polished sample (right).

The two BBO crystals samples had a section $3 \times 3 \mathrm{~mm}$ and a length of $3.155 \mathrm{~mm}$, and were cut for critical type-I second harmonic generation from $532 \mathrm{~nm}$ to,266 nm at a cut angle of $\theta=47.4^{\circ}$. Their optical facets have been polished with the same setup to a roughness below $8 \AA$, and were not AR coated. The crystals have been kept under dry air until the experiment.

3. Absorption and second harmonic generation measurements.

Their linear absorptions were measured from $190 \mathrm{~nm}$ to $700 \mathrm{~nm}$ using a Perkin Elmer Lambda 900 spectrometer. Their transmittances are displayed in Figure 2. The UV cut-off is located at $189 \mathrm{~nm}$ for both crystals, and no major differences between the different transmission curves are observed. From the transmittance values, the absorption coefficients were calculated. Their values near the cut-off wavelength are displayed in the inset of Figure 2.

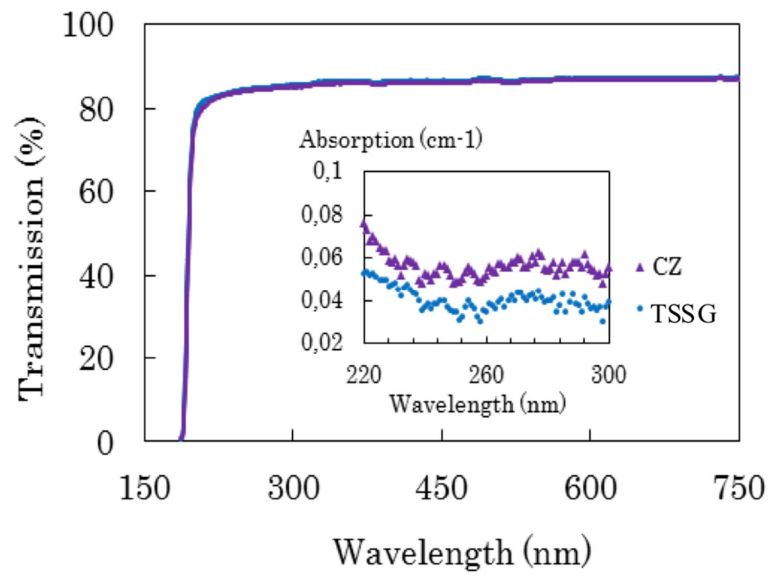

Figure 2: Transmission curves for CZ and TSSG crystals; inset: absorption curves near $257 \mathrm{~nm}$ for TSSG (blue circles) and CZ (purple triangles)

From these calculations, we extracted the absorption coefficient of both crystals at $257 \mathrm{~nm}$, which is equal to 0.033 $\mathrm{cm}^{-1}$ and $0.050 \mathrm{~cm}^{-1}$ for crystals TSSG and CZ respectively. We can notice several things from these measurements. First, both these values are below $0.06 \mathrm{~cm}^{-1}$, which is low compared to the $0.143 \mathrm{~cm}^{-1}$ previously reported for flux-grown BBO [7]. In high power experiments even a small absorption can induce a thermal dephasing strong enough to lower the conversion efficiency significantly [8]. A second remark is that the CZ BBO has a slightly higher linear absorption than the flux-grown crystal, which indicates that $\mathrm{CZ}$ growth itself is not enough to guarantee a lower absorption than a flux 
grown BBO. At these levels of absorption, parameters such as the base materials purity or growing environments strongly influence the final crystal transparency significantly. These parameters can vary a lot between a commercial grown crystal and a lab-grown one.

In order to confirm that both BBO crystals have similar nonlinear properties, a second harmonic generation experiment at low average power was conducted. The experimental set-up is displayed in Figure 3.

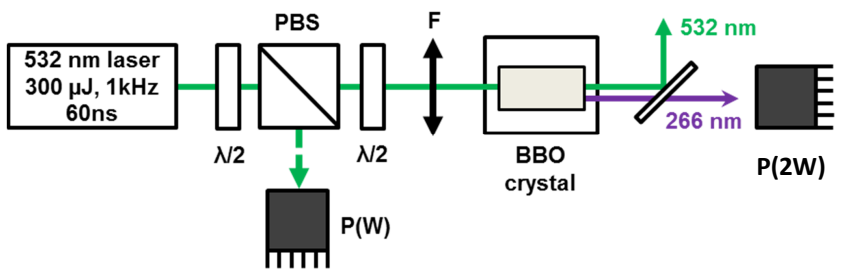

Figure 3: Experimental setup for SHG.

A low average power pulsed laser at $532 \mathrm{~nm}$ was used as the fundamental source. The laser has an average power of $300 \mathrm{~mW}$ at $532 \mathrm{~nm}$, at $1 \mathrm{kHz}$, and a pulse width of $60 \mathrm{~ns}$. It corresponds to a pulse energy of $300 \mu \mathrm{J}$ and peak power of $5 \mathrm{~kW}$. The laser output was focused into the nonlinear crystal at a beam waist of $\mathrm{w}_{0}=60 \mu \mathrm{m}$. The crystals were controlled in temperature at $20^{\circ} \mathrm{C}$ and placed on a rotation mount. The output beams were separated using a prism and an interferential filter is placed in front of detector. All the displayed values correspond to the corrected powers at the entrance and at the output of the crystal. For a maximum input power of $300 \mathrm{~mW}$ at $532 \mathrm{~nm}$, output powers of $16.6 \mathrm{~mW}$ and $16.3 \mathrm{~mW}$ were respectively measured for crystals TSSG and CZ, which represent second harmonic conversion efficiencies of 5.5\% and 5.4\% respectively. The results are presented in Figure 4.

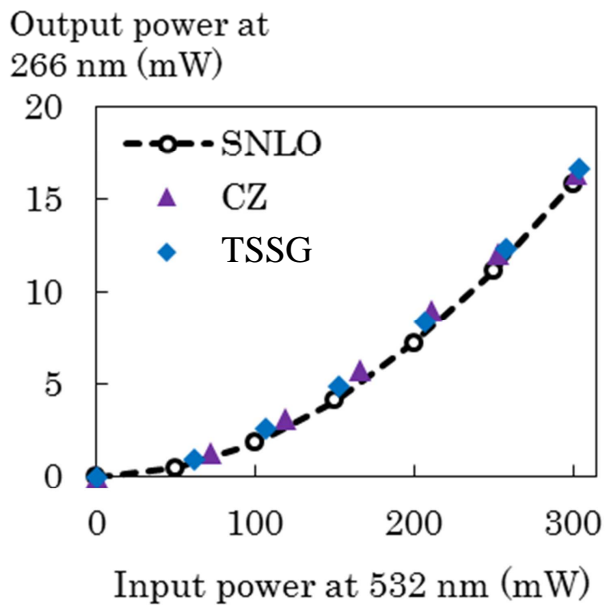

Figure 4: Output power at $266 \mathrm{~nm}$ versus input power at $532 \mathrm{~nm}$ for the low power SHG experiment. Blue diamonds: TSSG crystal; purple triangles: CZ crystal; black circles: SNLO simulations

They have been fitted with the simulation software SNLO [9]. As expected, the conversion efficiencies are extremely similar between the different crystals. At this average power level, the linear absorption doesn't induce thermal dephasing. Therefore, for low power SHG in the UV, there seem to be no advantages of using Czochralski-grown BBO.

There is a great demand in the micromachining industry for reliable, high repetition rate, pulsed deep-UV lasers around $260 \mathrm{~nm}$, which are not available commercially yet. Therefore, in order to explore our BBO crystal's potential for this application, we used a green nanosecond Yb-fiber laser at $515 \mathrm{~nm}$ from EOLITE SYSTEMS. The laser has an average power of $30 \mathrm{~W}$ at $515 \mathrm{~nm}$, at a repetition rate of $150 \mathrm{kHz}$ and a pulse width of $8 \mathrm{~ns}$. It corresponds to pulse energy of $200 \mu \mathrm{J}$ and a peak power of $25 \mathrm{~kW}$. The laser output has a Gaussian beam profile with a measured beam quality $\mathrm{M}^{2}$ below 1.2 . The laser pulses have a spectral width of $0.2 \mathrm{~nm}$. The spectral acceptance of a $3 \mathrm{~mm}$ long, type I $\mathrm{BBO}$ cut at $\theta=47.4^{\circ}$ can be calculated to be about $0.46 \mathrm{~nm}$, which is larger than our fundamental spectral bandwidth [9]. The experimental set-up is similar to the one displayed in Figure 2, except that the fundamental laser is now replaced with a powerful nanosecond pulsed laser. The fundamental green laser was focused inside the nonlinear crystal with a lens of focal length $\mathrm{f}=300 \mathrm{~mm}$ to obtain a $1 / \mathrm{e}^{2}$ beam waist of $\mathrm{w}_{0}=51 \mu \mathrm{m}$ inside the nonlinear crystal. We choose this beam 
waist size so the conversion efficiency could be maximized without damaging the crystal surface: it corresponds to a surface fluence in the green of $2.5 \mathrm{~J} / \mathrm{cm}^{2}$. The nonlinear crystal was placed inside an oven and heated at $100^{\circ} \mathrm{C}$. Since the phase matching angle for SHG of $515 \mathrm{~nm}$ is slightly different from the angle at $532 \mathrm{~nm}$, the crystal was rotated accordingly. The input $515 \mathrm{~nm}$ laser beam profile and output $257 \mathrm{~nm}$ beam profile are displayed in Figure 5 .
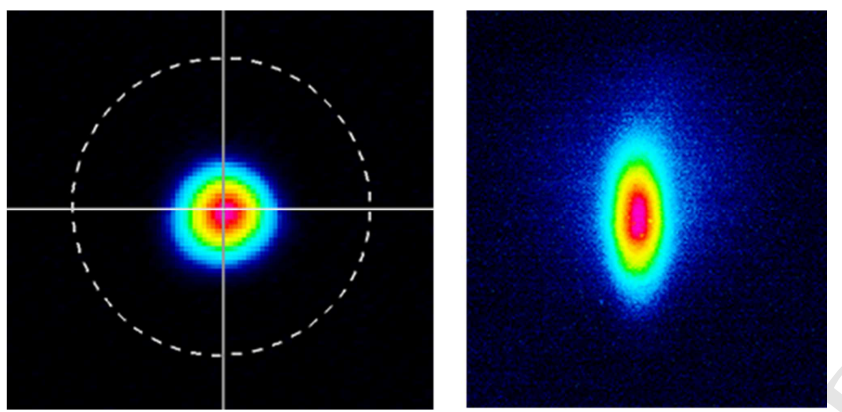

Figure 5: Beam profiles for $515 \mathrm{~nm}$ (left) and $257 \mathrm{~nm}$ (right)

The $257 \mathrm{~nm}$ beam profile was taken using a UV-beam converter, and is elliptical due to the narrow acceptance angle and large walk-off of BBO. The average output power at $257 \mathrm{~nm}$ for both crystals in function of the incident $515 \mathrm{~nm}$ average power is displayed in Figure 6. The theoretical results calculated with the simulation software SNLO are also included [9]. This software models the full 3D Gaussian profile, but doesn't model thermal effects. For a maximum input power of $30 \mathrm{~W}$ at $515 \mathrm{~nm}$, output powers of $2.15 \mathrm{~W}$ and $2.65 \mathrm{~W}$ were respectively measured for crystals TSSG and CZ, which represent second harmonic conversion efficiencies of $7 \%$, and $9 \%$. Errors bars of $5 \%$ were added on the experimental output powers values to account for the power measurement fluctuation.

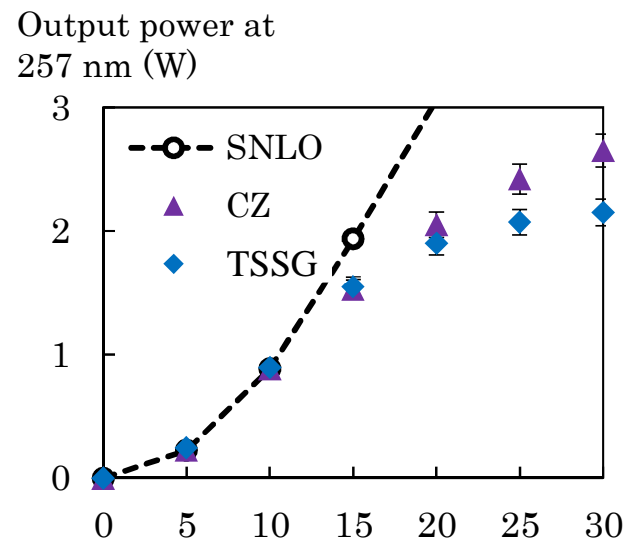

Input power at $515 \mathrm{~nm}(\mathrm{~W})$

Figure 6: Output power at $257 \mathrm{~nm}$ versus input power at $515 \mathrm{~nm}$ for high power SHG. Blue diamonds: TSSG crystal; purple triangles: CZ crystal; black circles: SNLO simulation

The crystal alignment was optimized for each input power value. The theoretical prediction with SNLO is that without thermal dephasing, an output power of $6.26 \mathrm{~W}$ should be reached. We can notice first that the theoretical model agrees very well with the measurements until $10 \mathrm{~W}$ of incident green average power. In order to see the differences between the different crystals, the theoretical points after the divergence with the experiment are not displayed. Then, we see with these measurements that the CZ-grown BBO gives a $20 \%$ higher output power at $257 \mathrm{~nm}^{-1 h a n}$ both fluxgrown BBO. This feature cannot be explained by linear absorption, as we measured that the CZ BBO had a slightly higher absorption than the flux-grown crystal. This result is very interesting, as all the previous works argued that the improved linear absorption of the CZ growth method was responsible for the better performances demonstrated in the UV.

One feature of BBO that could play a role in the observed experimental results is its high two-photon absorption coefficient. A two-photon absorption coefficient for flux-grown BBO of $B=25 \mathrm{~cm} / \mathrm{GW}$ at $266 \mathrm{~nm}, 10$ 
$\mathrm{kHz}$ and ambient temperature have been reported [10]. One way to verify this hypothesis is to simply change the operating temperature of the BBO crystals. Indeed, the two photon absorption coefficient can be strongly reduced with a higher temperature [11,12]. We did the experiment again with the TSSG and CZ crystal, and studied the maximum UV power obtainable by frequency conversion for operating temperatures of $30^{\circ} \mathrm{C}, 50^{\circ} \mathrm{C}$, $100^{\circ} \mathrm{C}, 150^{\circ} \mathrm{C}$ and $200^{\circ} \mathrm{C}$ and input power of $25 \mathrm{~W}$. The results are displayed in Figure 7 . We can see that when the $\mathrm{BBO}$ temperature rises, the output UV power increases. Between $30^{\circ} \mathrm{C}$ and $200^{\circ} \mathrm{C}$, the maximum UV output power increases from $2 \mathrm{~W}$ to $2.3 \mathrm{~W}$ with the TSSG crystal, and from 2.4 to $3.2 \mathrm{~W}$ with CZ crystal. With the temperature increase, the CZ-grown BBO now yields $40 \%$ more average UV power than the flux-grown BBO. A decreasing nonlinear absorption coefficient would reduce the thermal dephasing and increase the conversion efficiency. The crystal conductivity could also change slightly depending on the crystal growth condition, but such results have not been reported yet. The most convenient explanation of this effect is that the BBO crystals grown by TSSG contain sodium cations impurities since fluxes based on $\mathrm{Na}_{2} \mathrm{O}$ and $\mathrm{NaF}$ are used in growth processes. The article [13] showed correlation pattern between $\mathrm{Na}^{+}$value and observed laser beam scattering in TSSG BBO. The appearance of scattering centers in the crystals correlates with the high content of sodium whose critical concentration is about $0.021 \mathrm{wt} \%$. This article state that he effective distribution coefficient of sodium is $2.5-4.4 \times 10^{-3}$. That means that even highest quality TSSG BBO crystals have sodium impurity even if it's amount is less than detection limit of modern quantitative chemical methods. Thus, the effect of lower increasing of UV output power during the temperature rising in TSSG BBO unlike $\mathrm{Cz}$-grown BBO we correspond to sodium impurities in TSSG BBO crystals.

Output power at

$257 \mathrm{~nm}(\mathrm{~W})$

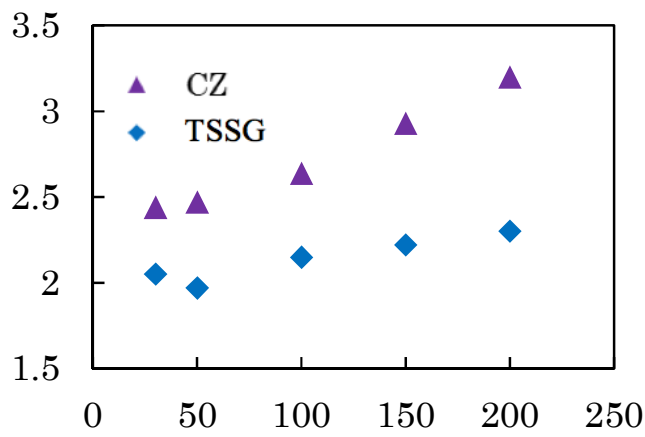

Crystal Temperature $\left({ }^{\circ} \mathrm{C}\right)$

Figure 7: Evolution of maximum output power at $257 \mathrm{~nm}$ depending on the crystal temperature. Blue diamonds: TSSG crystal; purple triangles: $\mathrm{CZ}$ crystal.

4 Conclusion.

In conclusion, we report a comparative study between the conversion efficiency to 266 and $257 \mathrm{~nm}$ of flux-grown BBO crystals and Czochralski grown BBO in two different pulsed regimes. We first characterize their linear absorption, and show that they were low for all crystals. Then, a low power SHG experiment was realized, and shows no differences between the different growth methods. Finally, a high power conversion experiment was realized with a $515 \mathrm{~nm}$ nanosecond green laser, we found that the CZ BBO yield a 40\% higher UV output power than the flux-grown BBO when the crystals were heated at $200{ }^{\circ} \mathrm{C}$. For the first time to the best our knowledge, we show that the enhanced performances of CZ-grown BBO are not directly linked to linear absorption, and that a detailed investigation on its nonlinear absorption properties is needed.

\section{Acknowledgement}

Loïc Deyra thanks Philippe Villeval for the BBO crystals polishing.

Loïc Deyra thanks the DGA for the funding of his $\mathrm{PhD}$. This work is supported by the French ANR agency (ANR UV-

Challenge, No ANR: 12-B504-0014-01) 
References

[1] T.-C. Chen and R. B. Darling, "Parametric studies on pulsed near ultraviolet frequency tripled Nd:YAG laser micromachining of sapphire and silicon," J. Mater. Process. Technol. 169 (2005) 214-218.

[2] T. Otani, L. Herbst, M. Heglin, S. V. Govorkov, and A. O. Wiessner, "Microdrilling and micromachining with diodepumped solid-state lasers," Appl. Phys. A 79, (2004).

[3] C. Chen, B. Wu, A. Jiang, and G. You, "A new type ultraviolet SHG crystal B-BaB ${ }_{2} \mathrm{O}_{4}$," Sci. Ser. B 28 (1985) $235-248$.

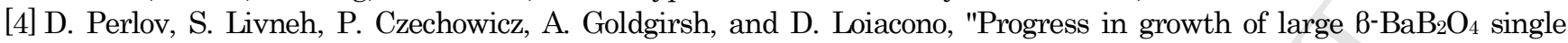
crystals," Cryst. Res. Technol. 46 (2011) 651-654.

[5] H. Kouta, Y. Kuwano, K. Ito, and F. Marumo, "8- $\mathrm{BaB}_{2} \mathrm{O}_{4}$ single crystal growth by Czochralski method. II," J. Cryst. Growth 114 (1991) 676-682.

[6] N. Umezu, T. Fukui, T. Okamoto, H. Wada, K. Tatsuki, K. Kondo, and S. Kubota, "Reliability of Czochralski-grown beta-BBO devices.pdf," in SPIE(1998).

[7] R. Bhandari, T. Taira, A. Miyamoto, Y. Furukawa, and T. Tago, "3 MW peak power at $266 \mathrm{~nm}$ using Nd: YAG / Cr 4 +: YAG microchip laser and fluxless-BBO," Opt. Mater. Express 2 (2012) 907-913.

[8] M. Takahashi, A. Osada, A. Dergachev, P. F. Moulton, M. Cadatal-raduban, T. Shimizu, and N. Sarukura, "Improved fourth harmonic generation in BBO by tight elliptical focusing perpendicular to walk-off plane.pdf," J. Cryst. Growth 318 (2011) 606-609.

[9] A. V. Smith, "Computer code SNLO (available from the authors at no charge)," (1997).

[10] M. Takahashi, A. Osada, A. Dergachev, P. F. Moulton, M. Cadatal-Raduban, T. Shimizu, and N. Sarukura, "Effects of Pulse Rate and Temperature on Nonlinear Absorption of Pulsed 262-nm Laser Light in B-BaB $\mathrm{O}_{4}$," Jpn. J. Appl. Phys. 49 (2010) 080211.

[11] M. Takahashi, G. Masada, I. Sekine, M. Cadatal, T. Shimizu, N. Sarukura, C. Byeon, V. Fedorov, S. Mirov, A. Dergachev, and P. F. Moulton, "Reduction of Nonlinear Absorption in $\mathrm{Li}_{2} \mathrm{~B}_{4} \mathrm{O}_{7}$ by Temperature- and Repetition RateControl," Jpn. J. Appl. Phys. 48 (2009).112502

[12] N. Kondratyuk and A. Shagov, "Nonlinear absorption at $266 \mathrm{~nm}$ in BBO crystal and its influence on frequency conversion," in Laser Optics (2002) 1-5.

[13] A.E. Kokh, N.G. Kononova, P.P. Fedorov, V.S. Boyarkov, R.M. Zakalyukin, and V.A. Chubarenko. Incorporation of alkali impurities into single crystals of barium metaborate $B-\mathrm{BaB}_{2} \mathrm{O}_{4} / / \mathrm{Crystallography}$ Reports, Vol. 47, No. 4, 2002, pp. 559-565. (Translated from Kristallografiya, Vol. 47, No. 4, 2002, pp. 616622.)

1. 
Hightlights

For deep UV $\lambda<260 \mathrm{~nm}$ barium borate $\beta$-BBO is major optical non linear material.

Crystal is produced in Na flux with Top seeding Solution Growth Process. A high purity b-BBO crystals are grown, by Czochralsky technics in a supercool melt. At low power incident intensity, both materials have similar efficiency. At high power intensity the Czochralski BBO presents $40 \%$ more efficiency. The temperature dependance of the output power shows the relation with non linear absorption effect . The interest for CzBBO crystal is started again. 